\title{
A STUDY ON THE PROFUNDA FEMORIS ARTERY AND ITS PERFO-
} RATOR BRANCHES

\section{S. Elizabeth Priyadarisini ${ }^{* 1}$, S. Chithra ${ }^{2}$.}

${ }^{* 1}$ Assistant Professor of Anatomy, Stanley Medical College, Chennai,Tamilnadu, India

${ }^{2}$ Professor and HOD of Anatomy,Stanley Medical College,Chennai,Tamilnadu, India.

\section{ABSTRACT}

Background: The profunda femoris artery is a branch of the femoral artery arising about 3-4 $\mathrm{cm}$ below the mid inguinal point.It is used in various radiologic imaging and vascular reconstructive procedures in the anterior thigh and hip region. Its circumflex branches are used in fasciocutaneous thigh flaps and its perforator branches are useful in breast reconstruction. The presence of such wide clinical applications has prompted this study on the profunda femoris artery and its perforator branches.

Materials and Methods: 50 adult lower limb specimens were obtained from the embalmed cadavers of the department of anatomy, Stanley medical college, Chennai. The femoral triangles were dissected and the profunda femoris artery with its branches exposed. The site of origin of the profunda from the femoral artery was identified.The distance of origin of profunda femoris artery from the mid inguinal point was measured using a measuring tape and variations present were studied. The perforator branches were also dissected and their branching pattern identified and photographed.

Results: Out of 50 lower limb specimens dissected, the profunda femoris artery was found to originate from the posterolateral aspect of the femoral artery in 32 cases(64\%), from the posterior side of the femoral artery in 12 cases $(24 \%)$ and from the lateral side in 6 cases $(12 \%)$.The mean length of origin of profunda femoris from the mid inguinal point was $4.31 \mathrm{cms}$. In 2 specimens (4\%) there was high origin of profunda femoris arising at a distance of $2 \mathrm{~cm}$ from the mid inguinal point. The perforating branches showed normal branching pattern in 40 specimens(80\%). In 8 specimens(16\%) there were five perforators and in 2 cases(4\%) there were six perforating branches arising from the profunda. The perforators were seen to arise from the lateral side of the profunda than from its medial side.

Conclusion: The knowledge of the branching pattern and variations of the profunda femoris artery and its perforators are useful to the surgeons to prevent iatrogenic complications while dealing with hip and anterior thigh regions. It will also be helpful to radiologists before planning various interventional procedures.

KEY WORDS: Femoral artery, Profunda femoris artery, Mid inguinal point, Perforators.

Address for Correspondence: Dr.S.Elizabeth Priyadarisini, Assistant Professor of Anatomy, Stanley Medical College, Chennai,Tamilnadu, India. E-Mail: drelizabethmmc@gmail.com

\begin{tabular}{|c|c|c|}
\hline \multicolumn{3}{|c|}{ Access this Article online } \\
\hline \multirow{2}{*}{$\begin{array}{l}\text { Quick Response code } \\
\text { DOI: } 10.16965 / \text { ijar.2017.128 }\end{array}$} & \multicolumn{2}{|c|}{$\begin{array}{l}\text { Web site: International Journal of Anatomy and Research } \\
\qquad \text { ISSN 2321-4287 } \\
\text { www.ijmhr.org/ijar.htm }\end{array}$} \\
\hline & $\begin{array}{l}\text { Received: } 28 \text { Jan } 2017 \\
\text { Peer Review: } 30 \text { Jan } 2017 \\
\text { Revised: None }\end{array}$ & $\begin{array}{l}\text { Accepted: } 02 \text { Mar } 2017 \\
\text { Published (O): } 31 \text { Mar } 2017 \\
\text { Published (P): } 31 \text { Mar } 2017\end{array}$ \\
\hline
\end{tabular}

\section{INTRODUCTION}

The profunda femoris artery (deep femoral artery) is the main branch of the femoral artery (FA) which originates about $3.5 \mathrm{~cm}$ distal to the inguinal ligament. In the upper thigh, the profunda femoris artery (PFA) gives origin to lateral and medial circumflex femoral arteries and to the perforator and muscular branches more distally.The perforator arteries are three in number and the termination of the PFA is 
called the fourth perforator.The perforator arteries pierce the adductor magnus and form a chain of anastomoses along the adductor muscles [1].

Profunda femoris artery is used for arteriography, ultrasound, doppler imaging, digital subtraction angiography and magnetic resonance imaging [2]. It is frequently used in vascular reconstructive procedures in the proximal leg [3]. Recent trends use profunda femoris for haemodialysis.The perforator branches of the PFA are used in anterolateral thigh flaps as long vascular pedicle during breast reconstruction after mastectomy [4]. Perforator fasciocutaneous flaps are also used in the reconstruction of ischial pressure sores [5].

\section{MATERIALS AND METHODS}

Fifty adult lower limb specimens were obtained from the embalmed cadavers at the department of Anatomy, Stanley Medical College, Chennai, Tamilnadu, India.

The femoral triangles were dissected and the femoral artery exposed completely. The profunda femoris artery arising about 3-4 cms below the mid inguinal point (MIP)was identified. The site of origin of the profunda femoris artery from the femoral artery was studied. The distance of origin of the PFA from the mid inguinal point was measured using a measuring tape. The adductor longus and adductor brevis were divided just below their origin and the attachment of adductor magnus to the femur noted. The perforating branches of the profunda femoris going under the tendinous slips of adductor magnus were carefully dissected, their origin and branching pattern studied. Variations in the origin of the profunda femoris artery and its perforators were identified and photographed.

\section{RESULTS}

The PFA originated from the posterolateral side of the FA in 32 cases (64\%), from the posterior aspect of the FA in 12 cases(24\%) and from the lateral aspect of the femoral artery in 6 cases(12\%). The mean length of profunda femoris origin from the femoral artery was found to be $4.31 \mathrm{cms}$. In 2 cases (4\%) there was high origin of PFA which arose at a distance of $2 \mathrm{cms}$ from the mid inguinal point
In 40 lower limbs (80\%) the perforator branches of the PFA showed normal branching pattern. In 8 cases $(16 \%)$ there were four perforators from the PFA and the artery itself continued down the lower thigh as the fifth perforator. In 2 cases (4\%) there were six perforating branches from the PFA.The origin of the perforators was mainly on the lateral side of the PFA than on its medial side.

Fig. 1: Profunda femoris artery arising from the posterolateral aspect of the femoral artery.

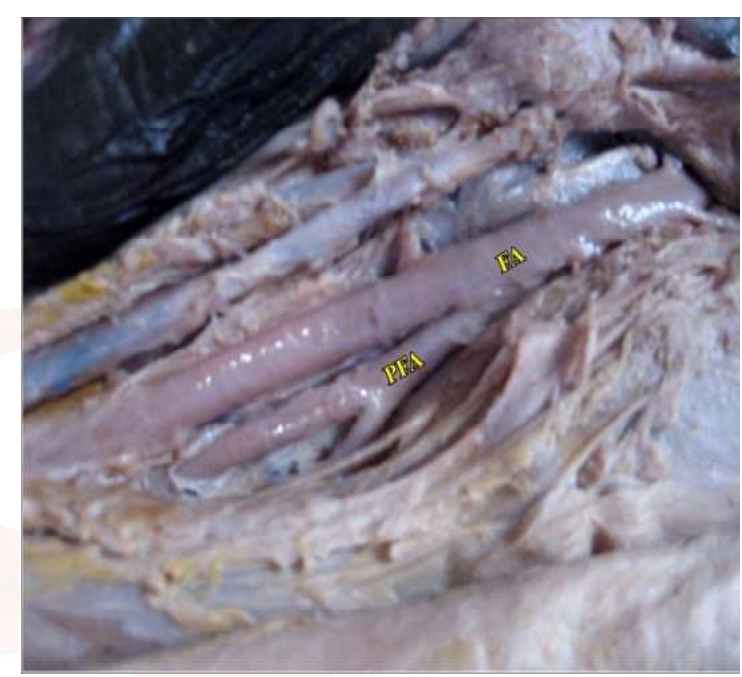

Fig. 2: Profunda femoris artery arising from the posterior side of the femoral artery.

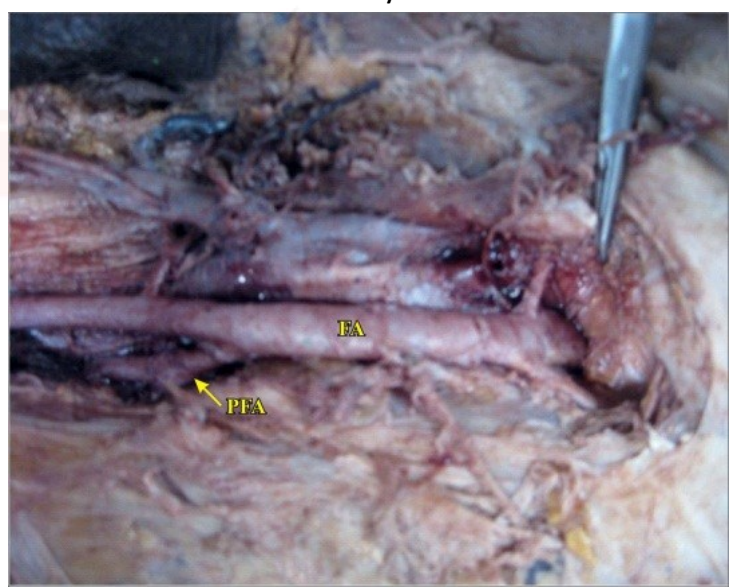

Fig. 3: Profunda femoris artery arising from the lateral side of the femoral artery.

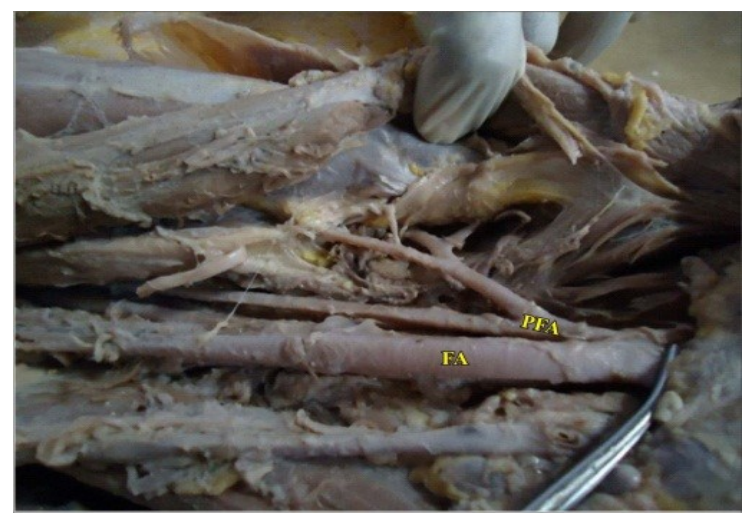


Fig. 4: High origin of profunda femoris artery.

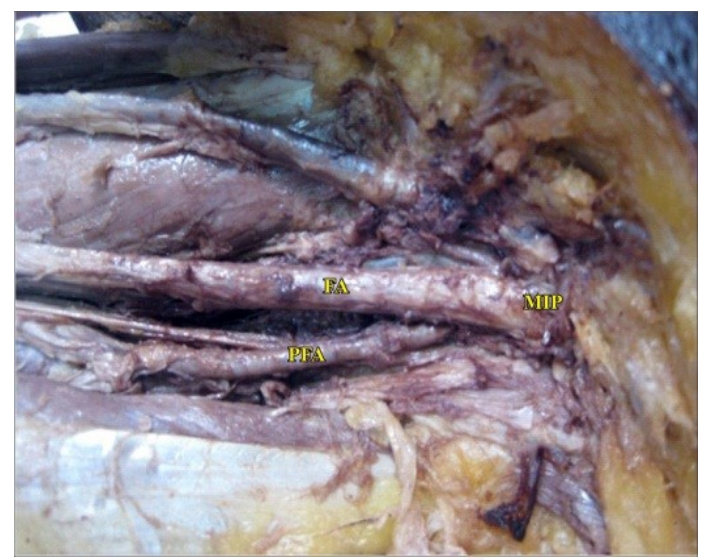

Fig. 5: Five perforator arteries arising from the profunda femoris artery.

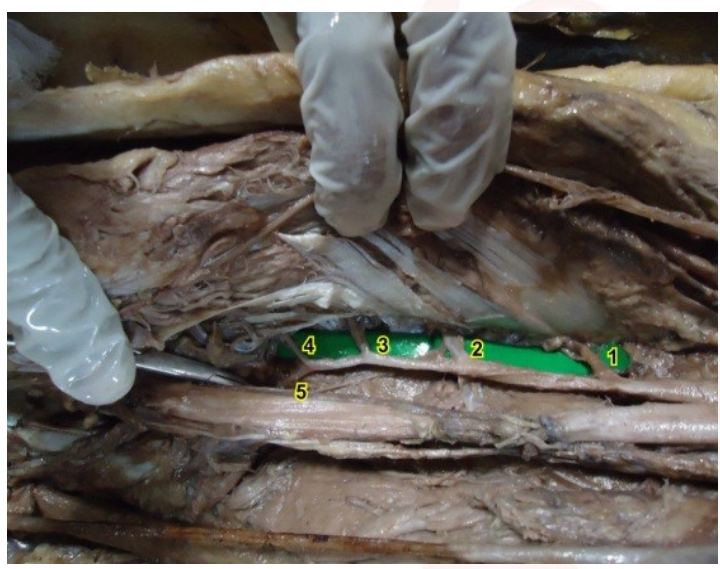

Fig. 6: Six perforator arteries arising from the profunda femoris artery.

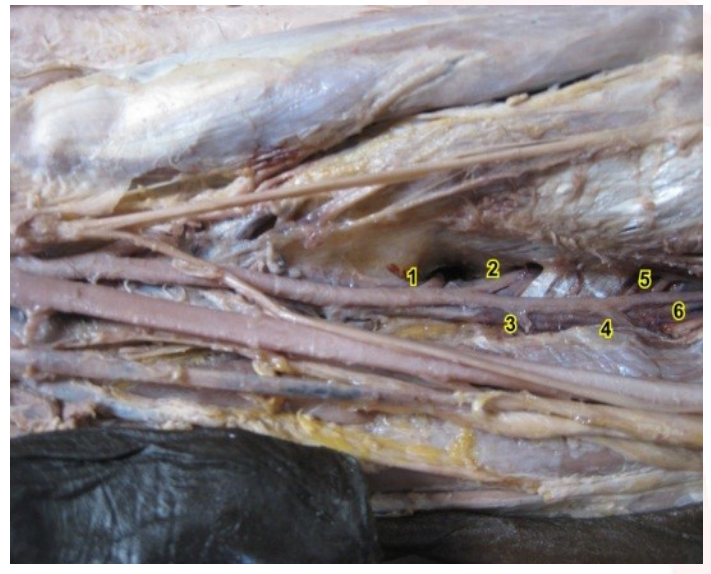

\section{DISCUSSION}

The profunda femoris artery arose from the posterolateral aspect of the femoral artery in $64 \%$ of cases in the present study. In Suthar K et al study [6] the PFA originated from the posterolateral side of the FA in 52\% and in Prakash et al study [7] it was $50 \%$. In a study by Daksha Dixit et al [8] the PFA arose from the posterolateral side of the FA in $42.1 \%$. The PFA originated from the posterior side of the FA in $31.25 \%$ in Dixit DP et al and in $44.64 \%$ in Siriporn et al study
[9]. In the present study it arose from the posterior side of the femoral artery in $24 \%$.The PFA arose from the lateral side of the femoral artery in $12 \%$ in the present study. Siriporn et al [9] reported lateral origin of the PFA to be $21.43 \%$.The PFA originated from the medial Aspect of the FA in $3.5 \%$ of cases in Prakash et al study [7], but there was no case of medial origin of PFA in our study.

The mean distance of PFA origin from the femoral artery in our study was $4.31 \mathrm{cms}$, which was similar to study by Siddharth P et al [3] who reported it to be $4.4 \mathrm{cms}$. MB Samarawickrama et al [10] observed distance of origin of PFA to be $5 \mathrm{cms}$ and Mamatha et al [11] found it to be $3.9 \mathrm{cms}$. In the present study high origin of PFA was noted $2 \mathrm{cms}$ from the mid inguinal point. High origin of PFA was also seen in Pooja Jain study [12] which was $2 \mathrm{~cm}$ from MIP and Mergu et al [13] reported high origin of PFA as $1 \mathrm{~cm}$ from the MIP. Vishal Kumar et al [14] reported a case of high origin of PFA where it arose just below the inguinal ligament.

In the present study, about $80 \%$ of the lower limbs showed normal branching pattern of perforators. This is similar to a Computerised tomographic study by Delong MR et al ${ }^{15}$ where $85 \%$ of the cases had three or more perforators. They were evenly distributed between the medial and lateral halves of the thigh. But in our study more number of perforators were seen arising from the lateral side of PFA than from its medial side.

\section{CONCLUSION}

Accurate knowledge of the origin, branching pattern and variations present in the profunda femoris artery and its perforator branches will be useful to the surgeons and orthopaedicians while planning surgeries in the hip and thigh regions. It will also be helpful to the radiologists for interpretation of images and to the clinicians before proceeding with interventional procedures.

\section{ABBREVIATIONS}

FA - Femoral Artery

PFA - Profunda Femoris Artery

MIP - Mid Inguinal Point 


\section{Conflicts of Interests: None}

\section{REFERENCES}

[1]. Susan standring [2008] Grays anatomy, 40 edition, Churchill Livingstone Elsevier, pg 1378-1380.

[2]. Dixit D P, Mehta L A, Kothari M L., Variations in the origin and course of profunda femoris, J Anat.Soc.India, 2001;50(1):6-7.

[3]. Siddharth P, Smith NL, Mason RA, Giron F., Variational Anatomy of the deep femoral artery,Anat Rec, 1985;212(2):206-209.

[4]. Kaplan JL, Allen RJ.,A Cost based comparison between perforator flaps and TRAM flaps, PlastReconstrSurg 2000;105(3):943-948.

[5]. Chae Min, In Sik Yun, Won Jai Lee.,ArchPlast Surg: 2014 Jul;41(4):387-393.

[6]. Suthar K, Patil D, Mehta C, Patel V, Prajapati B, Bhatt C., Cadaveric study: Morphological study of branches of femoral artery in front of thigh, CIB Tech Journal of Surgery, 2013 May-August;2(2):1622.

[7]. Prakash, JyotiKumari, A.KumarBhardwaj, Betty Anna Jose, S.KumarYadav, G.Singh., Variations in the origins of the profunda femoris, medial and lateral circumflex arteries: a cadaver study in the Indian population, Romanian Journal of morphology and embryology 2010,51(1):167-170.

[8]. Daksha Dixit, Dharati M Kubavat, Sureshbhai P Rathod, Mital M Pateld, Tulsibhai C Singel., A study of variations in the origin of profunda femoris artery and its circumflex branches, Int J Biol Res 2011;2(4):1084-1089.
[9]. SiripornThitilertdecha, ThanapornRungruang, CholladaVoraphattropas.,The origin of profunda femoris artery in Thais,Siriraj Med J 2012;64(Suppl 1):34-S36.

[10]. MB Samarawickrama, BG Nanayakkara, KWRW imalagunarathna, DG Nishantha, UB Walawage., Branching pattern of the femoral artery at the femoral triangle: a cadaveric study, Galle Medical Journal, 2009;14(1).

[11]. Mamatha H, Antony SylvianD'souza, Jessica S, Subani S., A cadaveric study on the variations in the origin, course and branching pattern of the profunda femoris artery, Int J Cur Res Rev, Oct 2012;04(19).

[12].Pooja Jain, RohiniMotwani., Bilateral variant branching pattern of femoral artery - A case report and embryological review, Int J Biol Med Res, 2013;4(3):3419-3421.

[13]. Mergu P, Prasad V S., Unique variation in origin and branching pattern of Profunda femoris artery-A case report, OA Anatomy 2014 Feb 01;2(1):5.

[14]. Vishal K, Vinay KV, Shishir K, Raghavendra AY., Anatomical variants of profunda femoris artery: among cadavers from South India., National Journal of Clinical Anatomy 2014;3(1):8-11.

[15]. De long MR., Hughes DB, Bond JE, Thomas SM, Boll $D T$, Zenn MR., A detailed evaluation of the anatomical variations of the profunda artery perforator flap using computerized tomographic angiograms, PlastReconstrSurg, 2014 Aug;134(2):186-192.

How to cite this article:

S. Elizabeth Priyadarisini, S. Chithra. A STUDY ON THE PROFUNDA FEMORIS ARTERY AND ITS PERFORATOR BRANCHES. Int J Anat Res 2017;5(1):3644-3647. DOI: 10.16965/ijar.2017.128 